\title{
UM OLHAR SOBRE O ENSINO DA ESTATÍSTICA NA BIBLIOTECONOMIA
}

\author{
Flavio Alexandre Massa Guimarães, Alexandre Sousa da Silva e Steven Dutt Ross \\ Universidade Federal do Estado do Rio de Janeiro, Brasil \\ flavio943@gmail.com
}

\begin{abstract}
Observando a dificuldade dos alunos de graduação em Biblioteconomia em compreender a estatística como ferramenta parte do cotidiano profissional, buscamos com base em autores (Mantovani, 2009; Nolan e Speed, 1999; Petocz e Reid, 2005; Rosenbaum,1971; and Silva et al. 1999) que trabalham com o ensino da estatística para as ciências sociais aplicadas realizar três experimentos com o objetivo de descrever características dos estudantes e suas relações com a estatística. No experimento 1 realizamos um teste de associação livre de palavras com dois estímulos ("Minha carreira me faz pensar em..." e "Estatística me faz pensar em..."). No experimento 2 foi realizado um questionamento sobre o conhecimento dos estudantes sobre aplicações de Estatística em Biblioteconomia, por fim, no esxperimento 3 realizamos um análise de rede de contatos com os estudantes.
\end{abstract}

\section{CONTEXTO}

Na Universidade Federal do Rio de Janeiro (UNIRIO) os estudantes de Biblioteconomia apresentam grande resistência em relação à Estatística, dessa forma, é necessário repensarmos a forma do ensino dessa disciplina.

Neste nova metodologia de ensino de Estatística é importante que o estudante perceba a utilidade e importância desta ferramenta em sua formação (Rao, 1986), uma vez que os estudantes, em geral não percebem a ligação entre a estatística e a biblioteconomia e este é o principal motivo do desinteresse pela disciplina.

\section{OBJETIVO}

Objetiva-se aqui apresentar e discutir algumas ferramentas de análise Estatística. No estudo 1 será aplicado o método TALP e criação de núvens de palavras; no estudo 2 pesquisar o conhecimento dos estudantes com relação às aplicações de Estatística em Biblioteconomia; por fim o estudo 3 é utilizado UCINET para contrução e análise das redes de contatos.

\section{RESULTADOS E DISCUSSÕES EXPERIMENTO 1}

Através do Teste de Associação Livre de Palavras (Alves-Mazzotti, 2008; Bihan-Poudec e Larose, 2010; Sousa et al. 2007) aplicamos dois estímulos na classe no primeiro dia de aula, os estímulos foram: "Minha carreira me faz pensar em..." e "Estatística me faz pensar em...". Nesse teste os estudantes tiveram um minuto para evocar 5 palavras, às primeiras que viessem à cabeça, para evitar a auto censura e tentar capturar os traços latentes com relação à carreira e à estatística. As duas palavras mais associadas à Estatística foram: Matemática e Cálculo. Representadas através de nuvens de palavras nas Figuras 1 e 2.

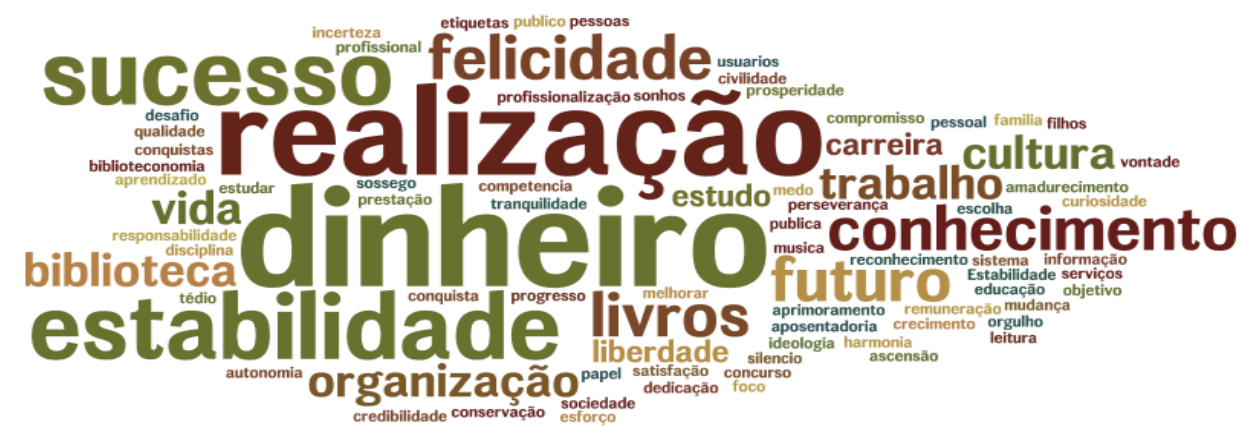

Figura 1. Nuvem de palavras, sentimentos sobre Biblioteconomia 


\section{CÁLCULO}

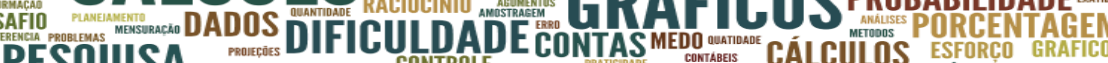

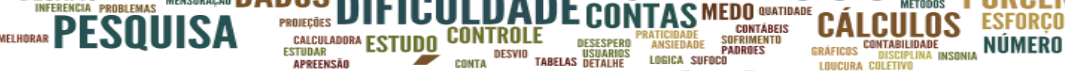

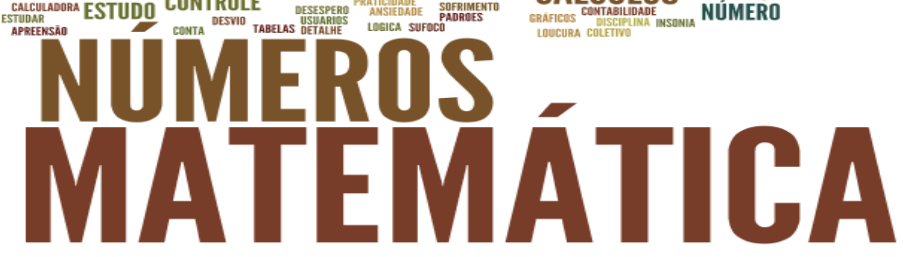

Figura 2. Nuvem de palavras, sentimentos sobre estatística

Desta forma, os sentimentos relacionados às experiências vivenciadas nas aulas de matemática, no ensino fundamental, acabam por influenciar diretamente o comportamento do estudante no curso de Estatística. Em outras palavras, o legado da matemática no ensino fundamental e médio tem efeito direto sobre a percepção da estatística.

\section{EXPERIMENTO 2}

O segundo experimento teve como objetivo avaliar a familiaridade dos estudantes com as aplicações de Estatística na sua área de conhecimento, este estudo foi realizado por meio de um breve questionário, no qual pergunta-se, para 42 alunos, diretamente quais áreas da biblioteconomia os interessam, se há aplicação de estatística e se já tiveram contato com alguma destas aplicações, para cada pergunta o aluno pode fornecer até quatro respostas.

Ao analisar os interesses dos alunos na biblioteconomia, percebemos que dos 42 alunos que responderam, foram levantadas 149 menções com repetições de interesses na área e os que mais foram citados são apenas 11 termos, mencionados 63 vezes e que representam $42 \%$ do total, conforme a Tabela 1.

Tabela 1. Os 11 interesses mais citados pelos alunos

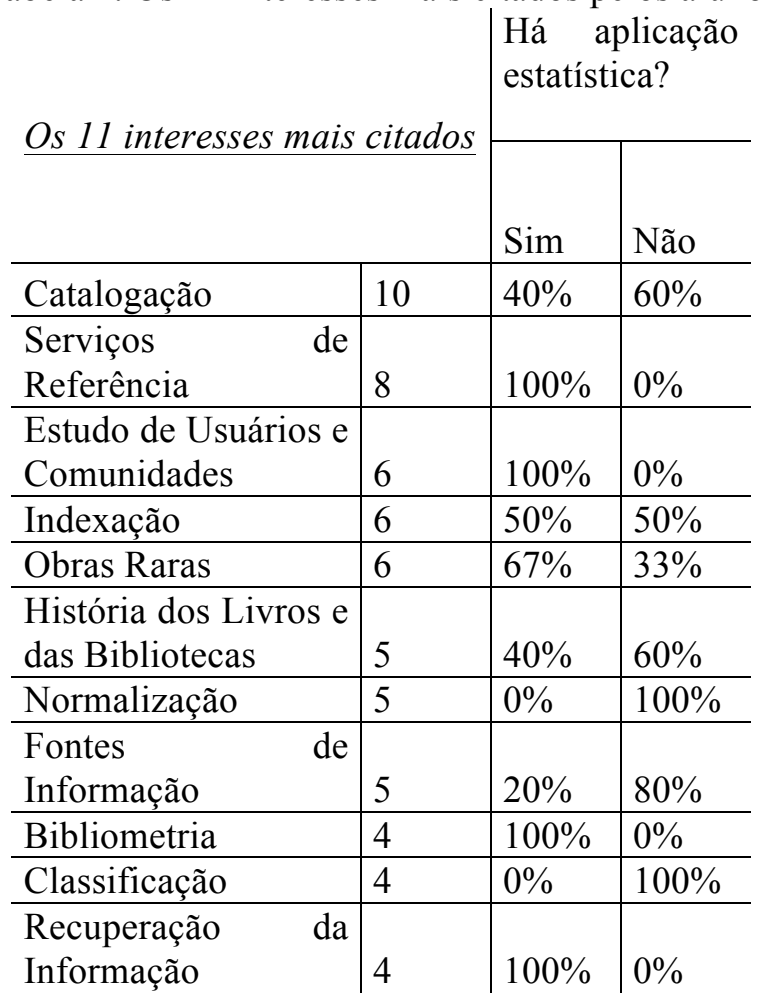


A identificação das áreas de interesse dos estudantes poderá ser utilizada como forma de motivá-los a pesquisar materiais com aplicações reais de Estatística em Biblioteconomia.

\section{EXPERIMENTO 3}

Por meio de redes de contato foi análisado a forma como a turma estava estruturada e como as relações (baseadas nos fatores de centralidade) afetam o tema escolhido pelo grupo a ser apresentado no Trabalho Final do Curso (TFC). Na execução do TFC (Bento e Barichello, 2011) a turma foi dividida em grupos com 5 membros cada, e cada grupo deveria escolher um tema em comum acordo entre os companheiros para trabalhar ao longo do curso além de descrever palavras chave sobre os temas.

Os estudantes pesquisam bibliografias sobre o tema que escolheram e começam a trabalhar conceitos estatísticos apresentados em sala de aula utilizando como ferramenta de análise, o programa estatístico $R$.

Para a construção da rede social foi gerado um questionário no Google Docs em que os alunos respondiam com quais pessoas eles tinham afinidades, não sendo computadas as afinidades com si próprias.

Figura 3 apresenta a rede de contato dos alunos. Na contrução desta rede foi utilizada o programa Ucinet.

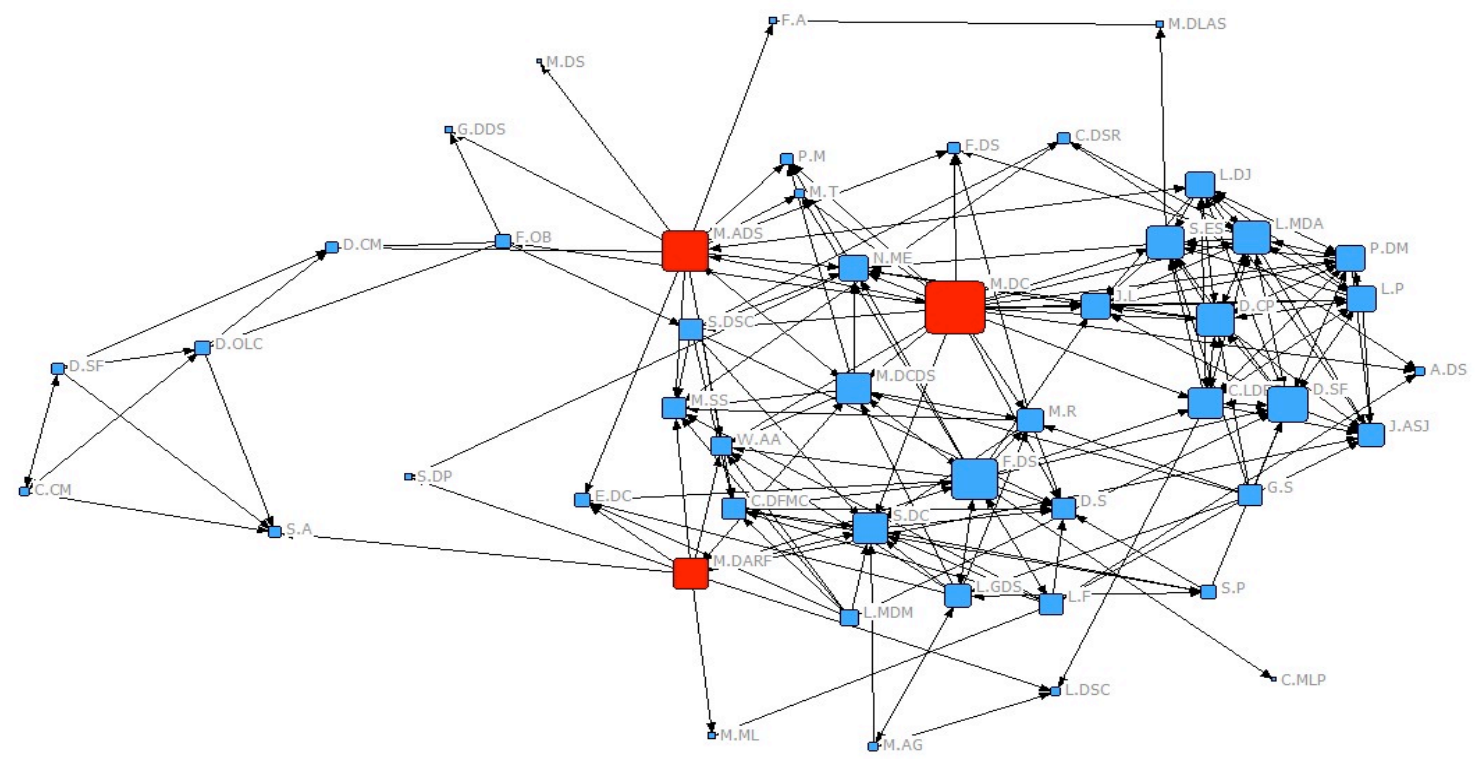

Figura 3. Atores centrais integrantes da rede social. Degree.

Os pontos avermelhados são os atores mais centrais da rede (Freitas, 2010; Rossoni et al. 2008), podemos dizer que estes mantém um alto grau de relação por relações diretas, indiretas, intermediação das relações e potencial de contatos através dos pares. Partindo deste ponto interessam analisar quais são os efeitos desse atores no grupos formados para o trabalho final.

Nas Tabelas 2, 3 e 4 podemos verificar os temas escolhidos dentro dos grupos dos três atores centrais.

O grupo de M.ADS era composto por M.DCDS, F.DS e M.T. Os interesses que esses indivíduos tinham em biblioteconomia são apresentados na Tabela 2.

Tabela 2. Conjunto de interesses em Biblioteconomia do grupo 1.

\begin{tabular}{l|l|l|l} 
M.ADS & Biblioteca pública & Recuperação da Informação \\
\hline M.DCDS & Metadados & Catalogação & Obras Raras \\
\hline F.DS & Não respondeu & \\
\hline
\end{tabular}




\section{\begin{tabular}{l|l} 
M.T & Não respondeu
\end{tabular}}

O grupo de M.DC era composto por esse indivíduo, F.DS e M.T. Os interesses que esses indivíduos tinham em biblioteconomia é apresentada na Tabela 3.

Tabela 3. Conjunto de interesses em Biblioteconomia do grupo 2.

\begin{tabular}{l|l|l} 
M.DC & Processamento Técnico & Recuperação da Informação \\
\hline N.ME & Não Respondeu & \multicolumn{2}{|l}{} \\
\hline P.M & Preservação & Catalogação
\end{tabular}

O grupo de M.DARF era composto por esse indivíduo, F.DS e M.T. Os interesses que esses indivíduos tinham em biblioteconomia é apresentada na Tabela 4.

Tabela 4. Conjunto de interesses em Biblioteconomia do grupo 3.

\begin{tabular}{l|l|l|l|lc} 
M.DARF & $\begin{array}{l}\text { Conservação } \\
\text { Curativa }\end{array}$ & Administração & Tesauro & \\
\hline C.DFMC & Obras Raras & Biblioteca Digital & Fontes de Informação & $\begin{array}{l}\text { Organização } \\
\text { Biblioteca }\end{array}$ & da \\
\hline C.MLP & Não Respondeu & & \\
\hline S.P & Não Respondeu & & \\
\hline M.DS & Não Respondeu
\end{tabular}

De cada grupo foi perguntado quais seriam as palavras chave que descreveriam os temas com os quais estariam trabalhando, e as palavras chave, foram respectivamente para o grupo 1: estudo de usuários, biblioteca pública, missão da biblioteca pública; grupo 2: estudo de usuários, comunidade escolar, estatística; grupo 3: cotas, universidades públicas, pesquisa e opinião.

Podemos observar que entre os três grupos com os atores mais centrais, dois trabalharam temas da área estatística. Apenas o grupo 1 trabalhou com um tema que fora uma área de interesse de um membro com alto grau de centralidade na rede. Logo podemos observar que embora os atores principais participem até de pequenos grupos, o comportamento deles se adapta ao meio para que possa haver o comum acordo entre os pares.

\section{CONCLUSÃO}

Conforme analisado nos experimentos com a turma pode ser observado que por trazerem muitos sentimentos negativos em relação a estatística, muitos deles não se envolvem com a disciplina, sendo necessário a aplicação de um exame a fim de diagnosticar os sentimentos, de forma pareada, entre biblioteconomia e estatística e sua aplicação interdisciplinar. Por fim as relações sociais não demonstram uma situação na qual os atores centrais ingfluenciam o grupo, e sim uma distribuição mais comunitária. A partir da situação encontrada na turma, houve um grande avanço no final, após o TFC, e posteriormente com a cada vez mais presente identificação interdisciplinar entre a biblioeconomia e a estatística produzirão frutos para ambas as areas.

\section{REFERÊNCIAS}

Alves-Mazzotti, A. J. (2008). Representações sociais: aspectos teóricos e aplicações à educação. Revista Múltiplas Leituras, 1(1), 18-43. https://www.metodista.br/revistas/revistasims/index.php/ML/article/viewFile/1169/1181.

Bento, M. H. S., \& Barichello, M. R. A. (2011). A metodologia de projetos como estratégia de aprendizagem na educação profissional e tecnológica. Práxis Educacional, 7(11), 175-190.

Bihan-Poudec, A, \& Larose, F. (2010). Social representations of french-speaking undergraduate students in humanities and social studies in the use and difficulties in learning statistics.

Freitas, L. Q. (2010). Medidas de centralidade em grafos. Coppe, Universidade Federal do Rio de Janeiro p.1-103. http://objdig.ufrj.br/60/teses/coppe_m/LeandroQuintanilhaDeFreitas.pdf. 
Mantovani, D. M. N. et al. (2009). Atitudes dos Alunos dos Cursos de Ciências Sociais Aplicadas em Relação à Estatística. Revista de Ciências da Administração, 11(25), 36-67. http://goo.gl/t7oXCa.

Nolan, D. \& Speed, T. P. (1999). Teaching statistics theory through applications. The American Statistician, 53(4), 370-375. http://www.stat.berkeley.edu/ nolan/Papers/tas.pdf.

Petocz, P. \& Reid, A. (2005). Something strange and useless: service students' conceptions of statistics, learning statistics and using statistics in their future profession. International Journal of Mathematical Education in Science and Technology, 36(7), 789-800.

Rao, I. K. R. (1986). Métodos quantitativos em Biblioteconomia e Ciência da Informação (1.ed.) Washington, Brasília: Organização dos Estados Americanos, Associação dos Bibliotecários de Brasília.

Rosenbaum, S. (1971). A Report on the Use of Statistics in Social Science Research. Journal of The Royal Statistical Society: Series A (General), 134(4), 534-610. http://www.jstor.org/stable/2343655.

Rossoni, L., Hocayen-da-Silva, A. J., \& Ferrerea Júnior, I. (2008). Aspectos estruturais da cooperação entre pesquisadores no campo de administração pública e gestão social: análise das redes entre instituições no Brasil. Revista de Administração Pública, Rio de Janeiro, 6(42), 1041-1067.

Silva, C. B., Carzola, I. M., Brito, M. R. F. (1999). Concepções e atitudes em relação à estatística. Conferência Internacional "Experiências e Expectativas do Ensino de Estatística - Desafios para o Século XXI". http://www.inf.ufsc.br/ cee/pasta1/art1.html.

Sousa, C. M. M. et al. (2007). Representações sociais do Biodireito elaboradas pelos estudantes de enfermagem e direito. Rev. Eletr. Enf., 1(9), 131-141.

http://www.fen.ufg.br/revista/v9/n1/v9n1a10.htm. 